\title{
Investigation and Assessment of the CFD for Horizontal Flow in the VHTR Core
}

\author{
Yan Shengyuan, ${ }^{1}$ Jean Luc Habiyaremye, ${ }^{1,2}$ Wei Yingying, ${ }^{1}$ and Cong Chi Tran ${ }^{1}$ \\ ${ }^{1}$ School of Electrical and Mechanical Engineering, Harbin Engineering University, Nantong Street, No. 145-1, P.O. Box 150001, \\ Harbin City, China \\ ${ }^{2}$ School of Science and Technology, University of Rwanda, P.O. Box 3900, Kigali, Rwanda \\ Correspondence should be addressed to Jean Luc Habiyaremye; habijealuc@yahoo.fr
}

Received 14 April 2017; Revised 21 August 2017; Accepted 17 September 2017; Published 26 October 2017

Academic Editor: Manmohan Pandey

Copyright (C) 2017 Yan Shengyuan et al. This is an open access article distributed under the Creative Commons Attribution License, which permits unrestricted use, distribution, and reproduction in any medium, provided the original work is properly cited.

\begin{abstract}
A nuclear power station using gas as a cooling medium has attracted so much attention because it offers high efficiency and greater safety. For a nuclear station that operates at a very high temperature, a gas-cooled reactor is fueled by uranium, moderated by graphite, and customarily cooled by helium. Nevertheless, throughout the operation, the bypass flow might be a result of a change in graphite shape that is caused by neutron damage. Core bypass and cross flows are significant elements to consider since the cross gap set hurdles to the flow field that are capable of diverting sufficient amount of coolant from reactor core location and initiating a possible fuel overheating. However, there is a great need to sufficiently validate this method by carrying out a thorough evaluation based on working environment analysis. Comparing the computed results with the existing data from Groehn's NHDA PMR-200 study was the only way to validate data. A model simulation was performed on a two-prismatic fuel block with a cross gap to examine the gaping size effect. Finally, the prediction methods for horizontal flow phenomena using a CFD technique and the field investigation results from the VHTR core were verified, and the identification of the horizontal flow behavior played a vital role in investigating the coolant velocity and pressure distribution in the horizontal gap.
\end{abstract}

\section{Introduction}

The reactors, type of Generation IV, present many advantages when compared to several reactors that were operational for decades ago [1]. The preferable nuclear power station on the market is the one that conforms to the prismatic core reactor (PMR-200) [2]. When pulled together, the hexagonshaped graphite blocks make the core of the PMR-200 reactor. Graphite blocks have the capabilities of resisting high temperature [3]. The block height was $793 \mathrm{~mm}$, and the block width was $360 \mathrm{~mm}$. Both vertical gaps and horizontal gaps existed in between the blocks and each block was armed with 108 coolant conduits whose diameter was $16 \mathrm{~mm}$ each. The characteristics of the flow in the core of the PMR reactor are complex since the interstitial gaps between reflector blocks divert the amount of coolant from the mainstream. This scenario can make the distribution of the cooling fluid difficult as a significant amount of coolant passes throughout bypass and horizontal gaps. The study allowed several layers of the fuel blocks to be concentrated in the areas of the PMR core. With the effect of temperature, the fuel blocks can have their shape expanded, and when exposed to fast neutron irradiation, their shapes shrunk. The wedge-shaped gap that appears in between the two fuel blocks is initiated by the effect of the shrinkage that deforms the fuel block axis.

The flow distribution happens to be very difficult at the core of the VHTR reactor when a leakage flow moves via the horizontal gap. Furthermore, the cross flow could cause the disproportionate distribution of the coolant and become a source of overheating associated with the release of fission product in the fuel element region. The behavior of the core cross flow must be evaluated to lessen its adverse effect on safety and enhance the efficiency of the VHTR [4]. Several surveys have been previously investigated and have shown the consequence of the horizontal flow scenarios in VHTR operations $[1,2]$. Nevertheless, it was found that the previous investigations were based on the fuel blocks whose shapes were differed from those of the NHDD PMR-200 reactor 


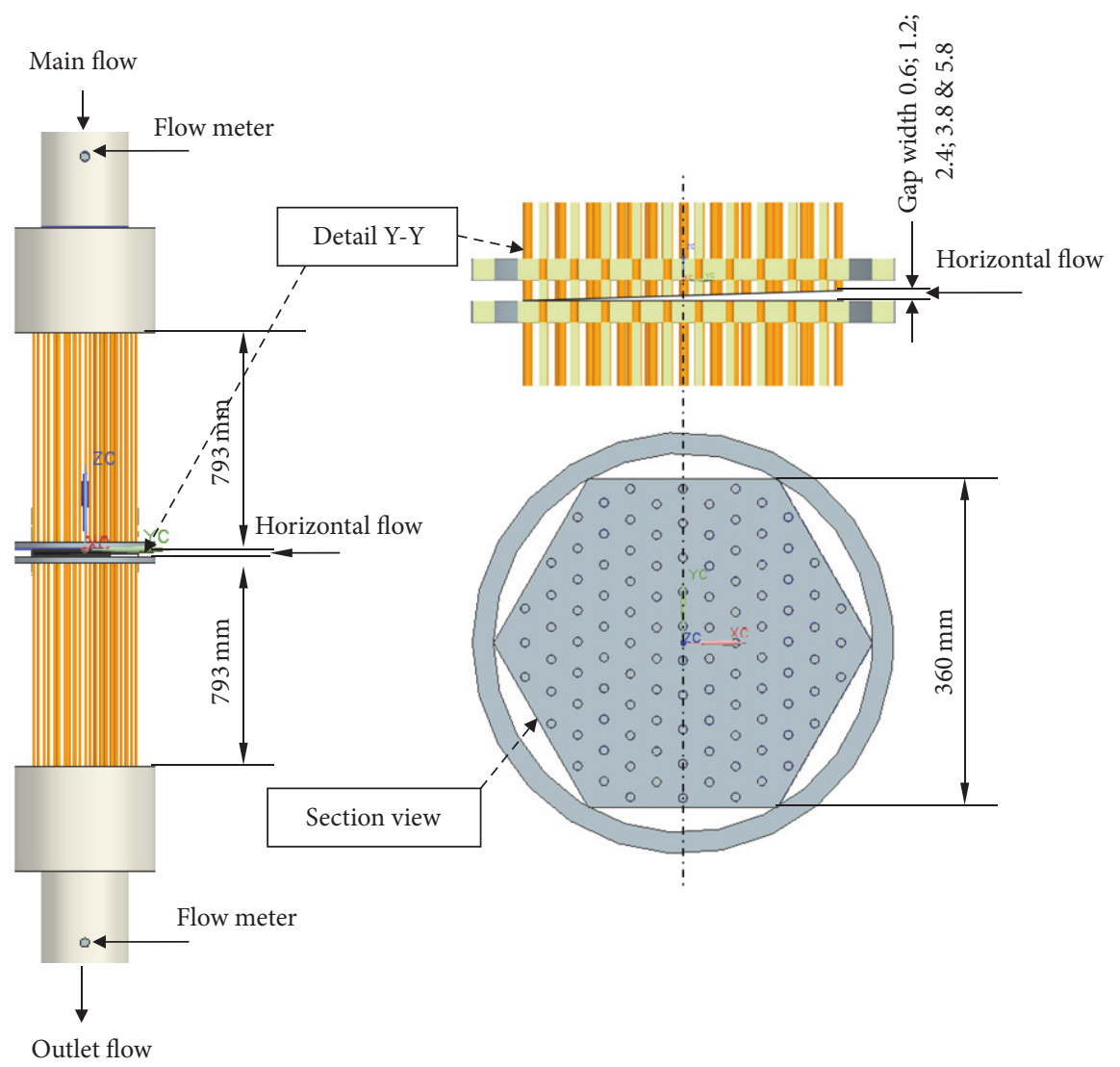

FIGURE 1: Simulation setup.

model and the loss coefficient of the horizontal flow was not adequately analyzed. The investigation of the cross flow for PMR-200 reactor core and the effectiveness of the coolant through a horizontal gap are necessary for designing the evaluation technique of the loss coefficient and establishing useful methods to analyze flow distribution in the PMR core.

Computing the correct loss coefficient will primarily help determine the quantity of flow that passes through the horizontal gap. This survey has designed an adequate simulation model equipped with an adjustable gap that was used to investigate horizontal flow scenarios. The assessment procedure of the cross flow comprises taking data of the stream at inlet and outlet and comparing the changes in both readings. The analytical data generated by the ANSYS CFX 13 were compared with the working environment data to confirm the verification of the CFD investigation method.

1.1. Examination Setup. This research developed an adequate simulation setup that considers a full-size testing model for accurate analysis of the horizontal flow behavior. The design provided in Figure 1 is a kind of adjustable opening between the fuel elements in the design setup. The analytical experiment was conducted under room conditions and working fluid (air) was flowing into the investigational model via the upper stream blocks, all the way to the lower stream blocks, and was discharged via the blower. The creation of the wedgeshaped gap was meant to adjust the horizontal gap, and the cross flow rate was examined by comparing the measured data of the flow rate at the entry point and that of the flow rate at the exit point. The simulation of the wedge-shaped gap was conducted, and the gap width was adjusted to $0.6,1.2,2.4,3.8$, and $5.8 \mathrm{~mm}$ and the outflow rates varying between 0.09 and $1.4 \mathrm{~kg} / \mathrm{s}$ correspond to the variation of the Reynolds numbers estimated between 3,900 and 54,200. The flow rate data were measured from six points located at the entry and exit points.

1.2. The Examination of the Horizontal Flow. The data resulting from the working analysis conducted during the evaluation of the horizontal flow went over the key points of the survey objectives and were diagrammatically explained. The correlation between the main flow rate and the horizontal flow rate is graphically represented in Figure 2, and it was found that as the horizontal flow increases, the primary flow rates also increase. The ratios of both flow rates were calculated to describe the characteristics of the horizontal flow (see Figure 3 ). The value obtained by dividing the mass flow rate of the horizontal flow $\left(M_{\text {horizontal }}\right)$ by the mass of the main flow rate at exit $\left(M_{\text {exit }}\right)$ of the lower stream blocks is described as the ratio of the horizontal flow rate (HR).

$$
\mathrm{HR}=\frac{M_{\text {horizontal }}}{M_{\text {exit }}} .
$$

It was confirmed that the ratio of the horizontal flow ratio almost remained steadily unchanged regardless of the 


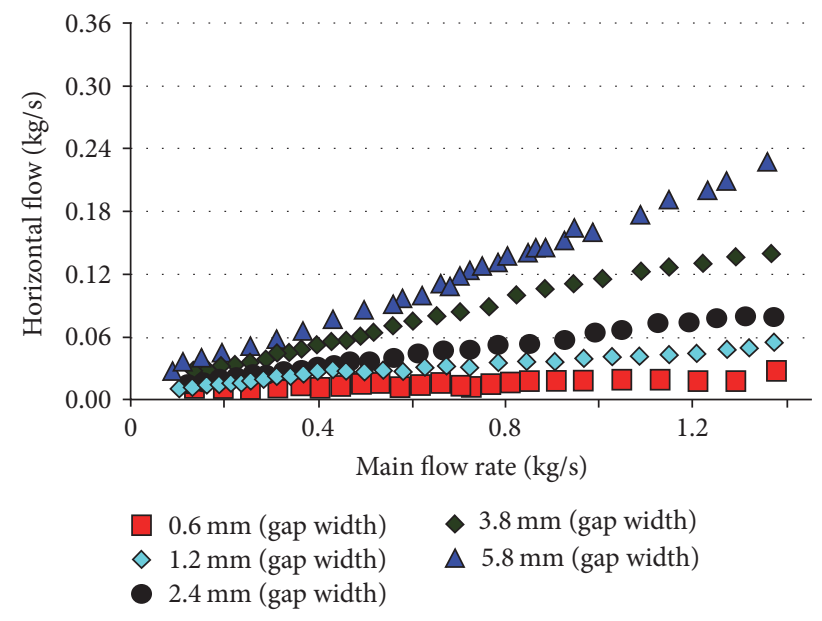

FIgURE 2: Horizontal flow versus main flow rate.

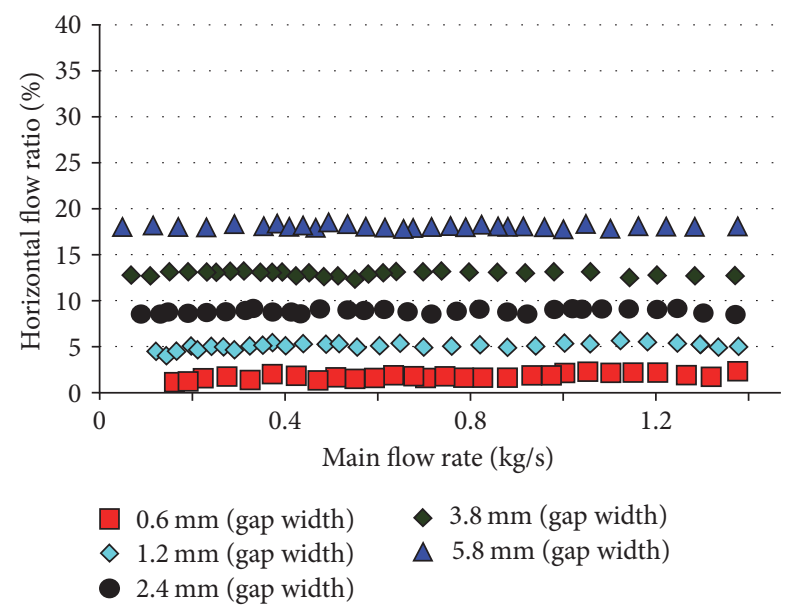

FIgURE 3: Horizontal flow ratio versus main flow rate.

changes in the primary flow rates. Some slight variations were noticed but are theoretically negligible since they cannot influence the decision.

The details of the correlation that exists between the cross flow ratio and the corresponding Reynolds numbers $\left(\mathrm{Re}_{\text {corresponding }}\right)$ are shown in Figure 4 . The next expression gives the corresponding Reynolds number

$$
\mathrm{Re}_{\text {corresponding }}=\frac{4 M_{\text {horizontal }}}{10 \mu t}
$$

where " $t$ " is the measured edge of the hexagon at horizontal gap, " $\mu$ " is the air viscosity, and " $M$ " is the mass flow rate at horizontal flow. During the investigation of the adjusted horizontal gap, the opening of the five faces of the horizontal gap is in contact with air flow. The horizontal flow demonstrated an increasing linear trend as the main flow rate was also increasing (see Figure 2) whereas the ratio of the horizontal flow rate appeared to maintain the linear trend and did not significantly change when the Reynolds number was increasing (see Figure 4). Furthermore, the ratio of the horizontal flow rate continued to be nearly constant

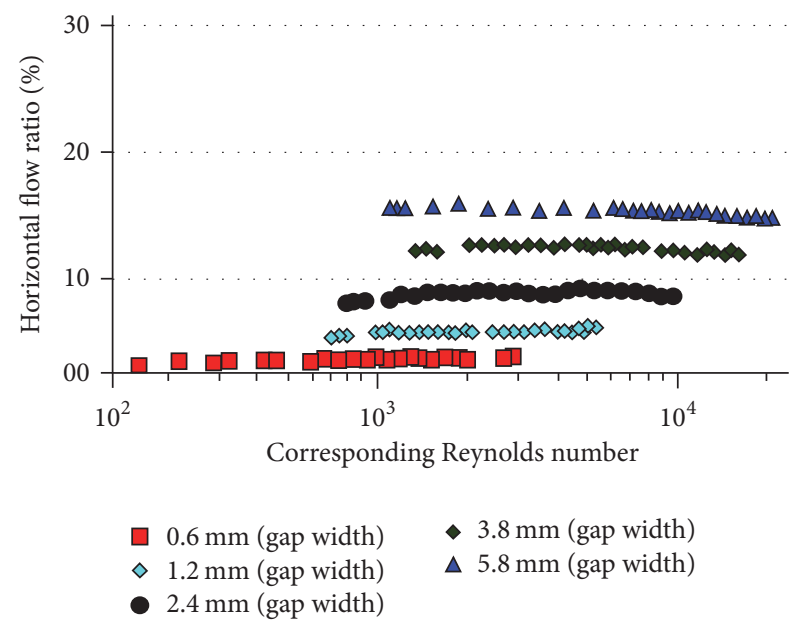

FIgURE 4: Horizontal flow versus Reynolds number.

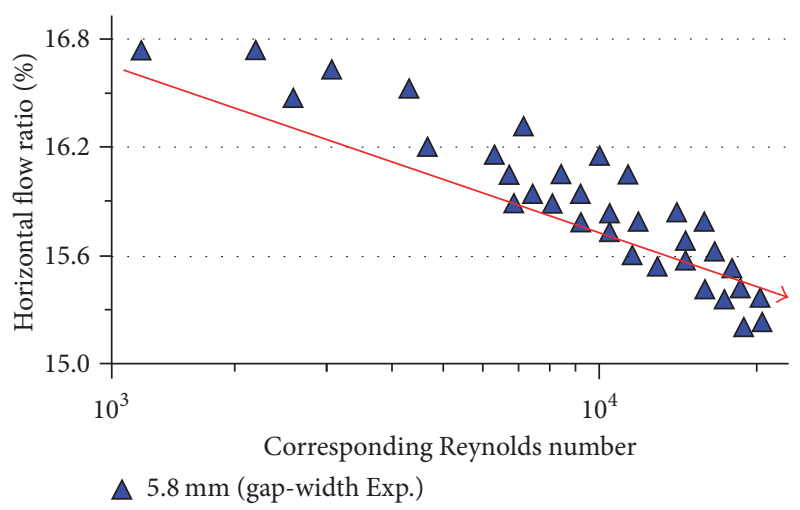

FIGURE 5: Horizontal flow ratio versus Reynolds number at $5.8 \mathrm{~mm}$.

throughout the test process, when on the other side the main flow rates were increasing (see Figure 3 ). It was seen that the ratio of the horizontal flow depended more on changes in gap size than on the corresponding Reynolds number or the main flow rate. This article confirmed the consequence of the gap size and gap shape all through the examination of the horizontal flow. Regardless the steady growth of the horizontal flow rate, the diagram gradient shows some differences in trend associated with the gap size when it is zoomed in. The horizontal flow ratio was decreasing while the Reynolds number was at the same time increasing when the gap width was adjusted to $5.8 \mathrm{~mm}$ (see Figure 5).

When the mass flow rate (primary flow) was between 0.09 and $1.4 \mathrm{~kg} / \mathrm{s}$ at $5.8 \mathrm{~mm}$, the corresponding Reynolds number was oscillating between 1,900 and 20,800. Subsequently, the flow characteristics were complex and cause turbulence scenarios. Figure 6 demonstrates that the ratio of the horizontal flow rate was following a steady trend when the gap width was $1.2 \mathrm{~mm}$. When the mass flow rate (main flow) was changing from 0.09 to $1.4 \mathrm{~kg} / \mathrm{s}$ at $1.2 \mathrm{~mm}$, the corresponding Reynolds number was varying between 450 and 4,500. As a result, since the diagram shows an abrupt change of the horizontal flow ratio, this study confirmed that there was a transition 


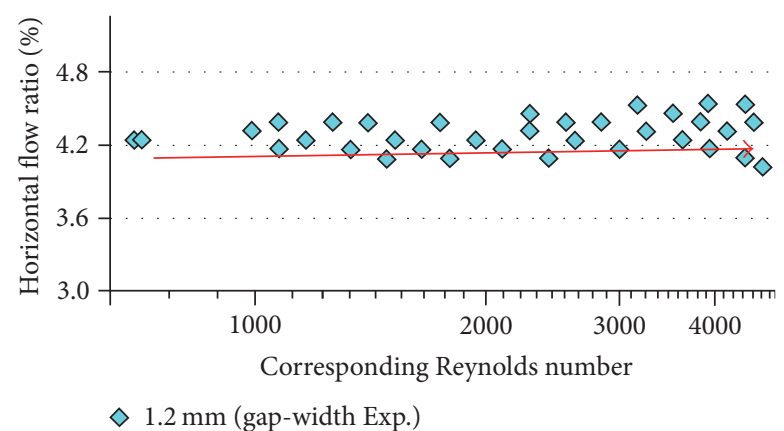

FIGURE 6: Horizontal flow ratio versus Reynolds number at $1.2 \mathrm{~mm}$.

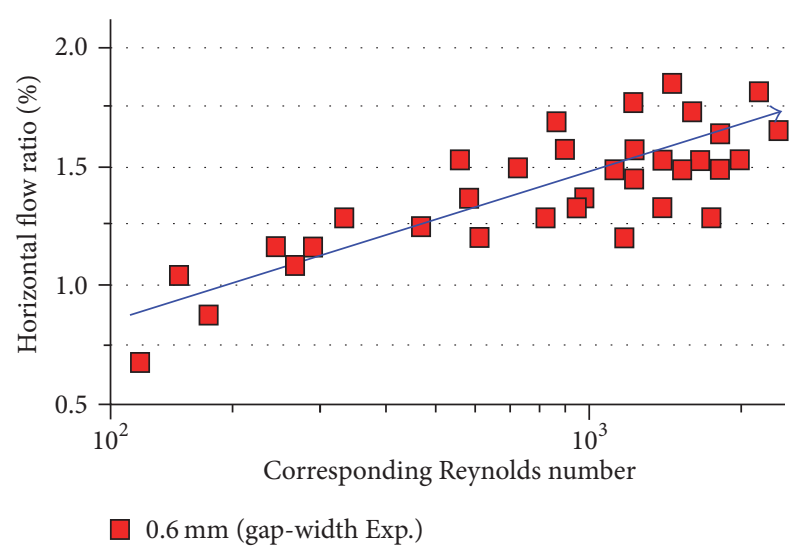

FIGURE 7: Horizontal flow ratio versus Reynolds number at $0.6 \mathrm{~mm}$.

from laminar flow to turbulence flow. As the ratio of the horizontal flow was growing, the corresponding Reynolds number was also increased when the horizontal gap size was set to $0.6 \mathrm{~mm}$. When the mass flow rate (main flow) was in the range starting from 0.09 to $1.4 \mathrm{~kg} / \mathrm{s}$ at $0.6 \mathrm{~mm}$, the corresponding Reynolds number was varying between 300 and 2,200, and Figure 7 confirmed the laminar flow was dominating the flow situations.

\section{The CFD Model Concepts}

The examination process took into consideration the empirical evaluation of the mass flow rate and the ratio of the horizontal flow. Then again, the loss coefficient could be obtained by computing the difference between the outside pressure and the pressure at the lower stream block. This research did not investigate the pressure variations process all over the length of the holes. The computational analysis has determined the loss coefficient of the horizontal flow, and the results confirmed the CFD model was valid. The CFD results were empirically validated after they were weighed against the measured data. The meshing analysis of the computational model with a gap width of $5.8 \mathrm{~mm}$ is explained in Figure 8 .

The GAMBIT 2.2.30 roughly produced a very fine meshing that is slightly less than nine million elements in this study. The examination process took place at room temperature, and conditions and wall $y+$ could roughly reach

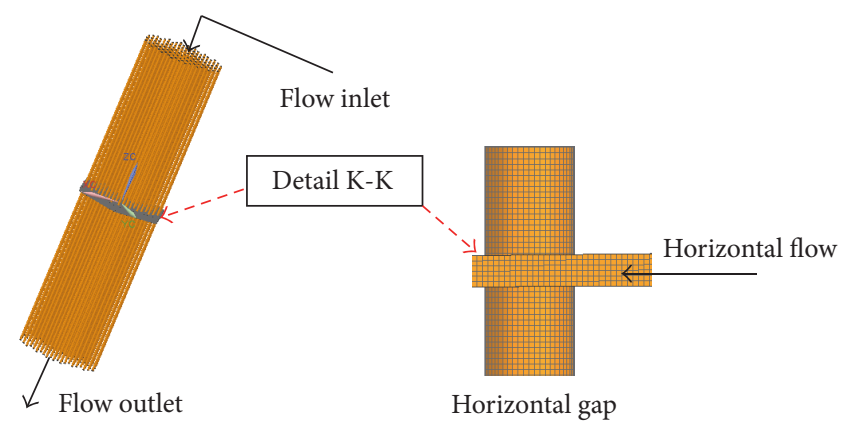

Figure 8: Meshing analysis $(5.8 \mathrm{~mm})$.

to 19. This paper suggested that the properties of the fluid remain unchanged after discovering that the drop of pressure in the maximum flow rate could hardly attain $4,650 \mathrm{~Pa}$. The turbulence analysis techniques applied the equation of the standard Reynolds Navier-Stokes (RNS) to compute shear stress transport (SST) model with an automatic wall surface finish [5]. The robust $k-\varepsilon$ turbulence relation and the $k$ $\omega$ baseline relation can produce high-accuracy results for the flow with separation [6]. Furthermore, the application of the transitional Gamma-Theta model was confirmed to be able to produce better results [7]. The potentially entire high-resolution scheme was used to examine the transport of the fluid's bulk motion and turbulent flow properties throughout the analysis [8]. The examination circumstances could sometimes impose slight computations changes, and the iterative resolution's CFD convergence was not exceeding $10^{-5}$. Appropriate boundary conditions were set for the entry and exit of fluid flow, wall surface, and the horizontal gap. This survey supposed that the cooling fluid flows in a smooth wall without skidding.

2.1. Meshing and Evaluation of Grid Convergence. The examination of the grid convergence was performed considering the flow rate of $1.0 \mathrm{~kg} / \mathrm{s}$ at exit, with $5.8 \mathrm{~mm}$ gap width and a fine meshing of 8.8 million elements and a range of course meshing whose grids are 4.1 million, 1.8 million, and 0.75 million elements.

The summarized data provided in Table 1 were collected when the gap size was set to $5.8 \mathrm{~mm}$. It determined the significance of the important measuring parameters such as pressure drop and mass flow rates with regard to the variations of the grid concentration (see Table 1).

The correlation between the mesh grid concentration and the mass flow rates at the horizontal gap is explained in Figure 9. The technique of extrapolating the Richardson value was numerically used to analyze and enhance the rate of convergence of sequence $[9,10]$. When the grid concentration increases, the pressure drop and mass flow rate are decreasing. An interesting scenario happens when the pressure drop sharply reduced between 0.75 and 1.8 million elements, and the interval ranging from 1.8 to 8.8 million elements corresponded to a steadily declining trend. Moreover, the mass flow rate was decreasing steadily from 0.75 to 8.8 million elements (see Figure 9). 
TABLE 1: Mass flow rates and pressure drop versus grid concentration.

\begin{tabular}{lcc}
\hline Number of elements & $\begin{array}{c}5.8 \mathrm{~mm} \text { gap width } \\
\text { Pressure drop }(\mathrm{Pa})\end{array}$ & $\begin{array}{c}\text { Mass flow rates } \\
(\mathrm{kg} / \mathrm{s})\end{array}$ \\
\hline 8.8 million & 3879.7 & 0.1531 \\
4.1 million & 3916.6 & 0.1552 \\
1.8 million & 3961.2 & 0.1582 \\
0.75 million & 4243.5 & 0.1619 \\
Extrapolation value & 3865.475 & 0.1525 \\
\hline
\end{tabular}

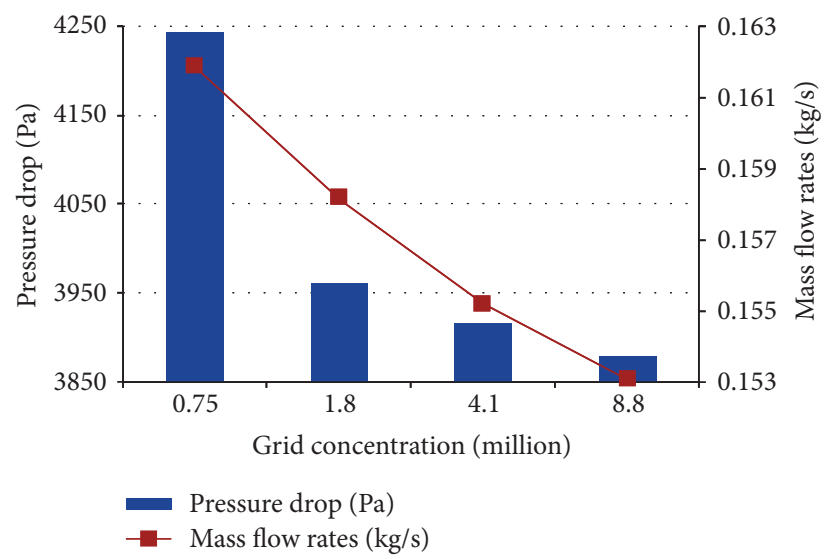

FIGURE 9: Pressure drop versus mass flow rate and grid concentration.

2.2. Discussions of Results. The process of validating the CFD model depended on conducting a comparison between empirical and computation outcome (see Figures 10 and 11). Figure 10 explains the correlation between the horizontal flow ratio and corresponding Reynolds number at $5.8 \mathrm{~mm}$ and Figure 11 gave details of the situation when the gap width was set to $0.6 \mathrm{~mm}$. The computation results obtained from a CFD examination revealed there was a good conformity with the working condition results (see Figures 10 and 11). In this survey, the simulation analysis found a remarkably decreasing course line of the horizontal flow ratio with $5.8 \mathrm{~mm}$ gap size and an increasing slope with $0.6 \mathrm{~mm}$ gap width.

Therefore, this paper confirmed the presence of laminar and turbulent situations and the achievement of high accuracy of the CFD investigation. Nevertheless, by analyzing the system with the gap width between 1.2 and $2.4 \mathrm{~mm}$, the results appeared inconsistent. It means that the observational data were at given points underestimated when the main flow rate was low during the CFD computation process.

Nevertheless, once the observational findings with the computational data were compared, the level of disagreement was oscillating between $-2 \%$ and $+2 \%$. But, considering the uncertainty due to working environment, the degree of the inconsistency is believed to be insignificant. The lumped parameter code associated with the accurate pressure loss coefficient is an essential aspect to consider in estimating the

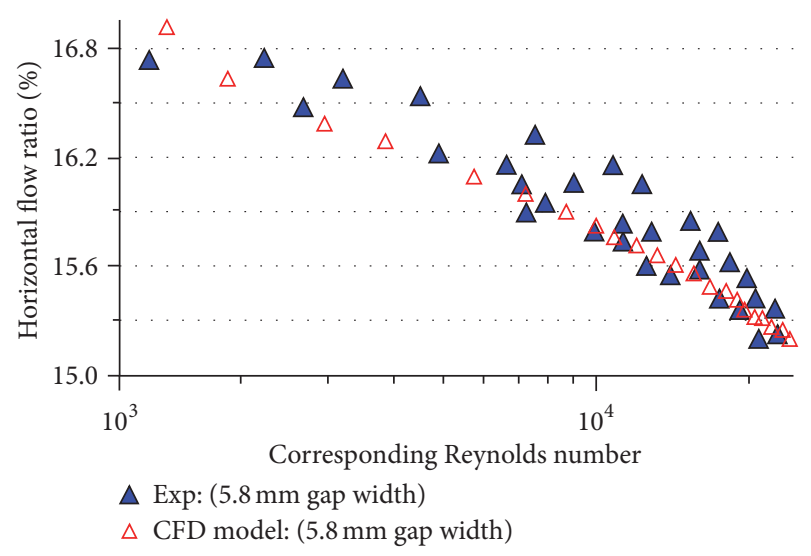

FIGURE 10: CFD model versus empirical results $(5.8 \mathrm{~mm})$.

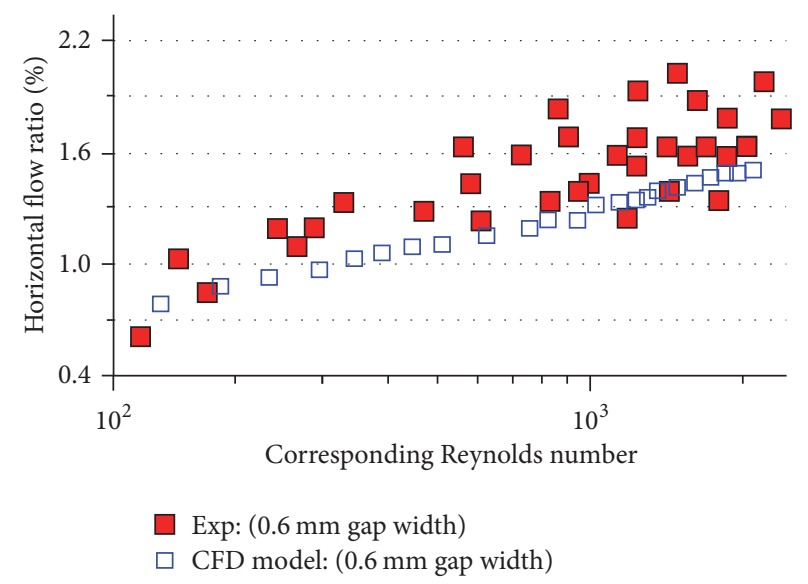

Figure 11: CFD model versus empirical results $(0.6 \mathrm{~mm})$.

changes in horizontal flow. Having computed the pressure variations between the blocks and the pressure loss through the horizontal gap, we can calculate the horizontal flow rate using the lumped parameter code. Some variables from the CFD investigation data must be examined to compute the corresponding loss coefficients for the said system. The loss coefficient " $K$ " in (3) depends on the pressure drop " $\Delta P$ " and the velocity of the horizontal flow " $v$."

$$
K=\frac{2 \Delta P}{\rho v^{2}} .
$$

Following the examination of the CFD model, the average pressure that goes via the cooling fluid conduits could contribute in estimating the loss coefficient for the horizontal gap. This paper also used the velocity computed in the CFD model investigation for uniformity purpose. Figure 12 shows that the loss coefficient was decreasing while the corresponding Reynolds number was increasing. However, at a given point, the loss coefficient course line appeared constant when the Reynolds number reached around 1,400. The diagrams that explained the relationship between the loss coefficient of the horizontal flow and the corresponding Reynolds number also gave the explanation of the existence of some discrepancies in the horizontal flow ratio regarding the main flow rate. 


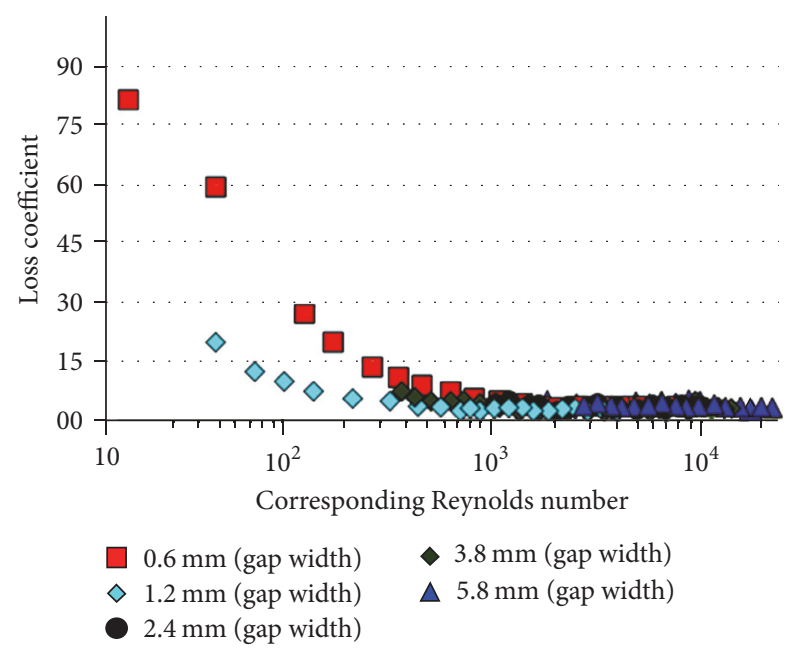

FIGURE 12: Loss coefficient versus corresponding Reynolds number.

As we know the decrease of the loss coefficient corresponds to the increase in the horizontal flow; this scenario took place in the analyses that involved a gap width of $0.6 \mathrm{~mm}$. It was discovered that the friction factor in rough pipes could present the same trend as loss coefficient. Several surveys investigated the friction factor and confirmed that it follows a decreasing course line when corresponding Reynolds number increases. The friction factor in rough pipes presents a constant trend in the event of turbulence scenarios because it depends solely on the wall treatment $[11,12]$.

As a result, the corresponding Reynolds number appeared to exert an undeniable influence to the horizontal flow and dictate its behavior. Based on the application of the lumped parameter code, the findings of this investigation should be useful in the development of the correlation that exists between the pressure loss coefficient and the estimation of the horizontal flow rate.

\section{Conclusions}

This research has explained the horizontal flow phenomena in the core of PMR200 reactor basing on the working condition assessment conducted during the evaluation process. A modifiable wedge-shaped horizontal gap was at the center of the assessment that involved readjusting the gap width and taking readings at various flow rates. Besides, the technical evaluation validated the prediction capacity of the CFD examination technique, and the assessment of the local flow phenomena was verified. This article confirmed that computational and empirical outcome data from both conditions were in good agreement. At some extents, the CFD model could underestimate the transition from laminar to turbulent flow, but the level of error was too weak to alter the overall results. It was found that the horizontal flow depends highly on the horizontal gap width and is less dependent on the main flow rate. For any corresponding Reynolds number less than 2,400, the horizontal flow rate was increasing, and the results showed a decreasing situation when the number is greater than 2,900. It was confirmed that, for the fuel blocks of
PMR200, the pressure loss coefficient kept a declining trend when the corresponding Reynolds number was increased from 10 to 1,400 . However, for any values larger than 1,400, the pressure loss coefficient turned out to be constant.

\section{Conflicts of Interest}

The authors declare that they have no conflicts of interest.

\section{Acknowledgments}

The research team gratefully acknowledges the financial and academic support of the Chinese Scholarship Council in conjunction with Harbin Engineering University and University of Rwanda.

\section{References}

[1] H. Kaburaki and T. Takizuka, "Crossflow characteristics of HTGR fuel blocks," Nuclear Engineering and Design, vol. 120, no. 2-3, pp. 425-434, 1990.

[2] H. G. Groehn, "Estimate of cross flow in high temperature gascooled reactor fuel blocks," Nuclear Technology, vol. 56, no. 2, pp. 392-400, 1982.

[3] N.-I. Tak, M.-H. Kim, H. S. Lim, and J. M. Noh, "A practical method for whole-core thermal analysis of a prismatic gascooled reactor," Nuclear Technology, vol. 177, no. 3, pp. 352-365, 2012.

[4] W. Gretler and M. Baltl, "Numerical calculation of fully developed turbulent flow in curved channels: an extended algebraic Reynolds-stress model," Forschung im Ingenieurwesen, vol. 66, no. 3, pp. 138-146, 2000.

[5] T.-H. Shih, W. W. Liou, A. Shabbir, Z. Yang, and J. Zhu, "A new $k$ - $\epsilon$ eddy viscosity model for high reynolds number turbulent flows," Computers \& Fluids, vol. 24, no. 3, pp. 227-238, 1995.

[6] R. H. Bush and M. Mani, "A two-equation large eddy stress model for high sub-grid shear," AIAA paper, vol. 2561, 2001.

[7] F. R. Menter, R. B. Langtry, S. R. Likki, Y. B. Suzen, P. G. Huang, and S. Völker, "A correlation-based transition model using local variables - Part I: Model formulation," Journal of Turbomachinery, vol. 128, no. 3, pp. 413-422, 2006.

[8] D. Drikakis, "Advances in turbulent flow computations using high-resolution methods," Progress in Aerospace Sciences, vol. 39, no. 6-7, pp. 405-424, 2003.

[9] P. J. Roache, Verification and validation in computational science and engineering, vol. 895, Hermosa Albuquerque, 1998.

[10] W.-M. Zhang, "Calculation of numerical uncertainty using Richardson extrapolation: application to some simple turbulent flow calculations," Journal of Fluids Engineering, vol. 117, p. 439, 1995.

[11] G. O. Brown, "The history of the Darcy-Weisbach equation for pipe flow resistance," in Environmental and Water Resources History, pp. 34-43, 2003.

[12] E. Romeo, C. Royo, and A. Monzón, "Improved explicit equations for estimation of the friction factor in rough and smooth pipes," Chemical Engineering Journal, vol. 86, no. 3, pp. 369-374, 2002. 


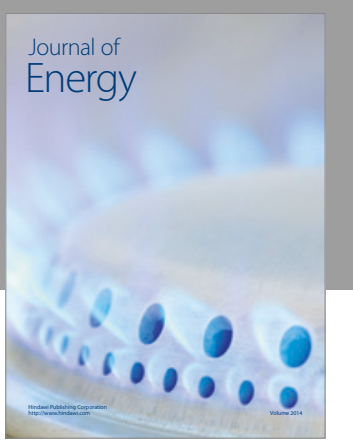

Journal of

Industrial Engineering
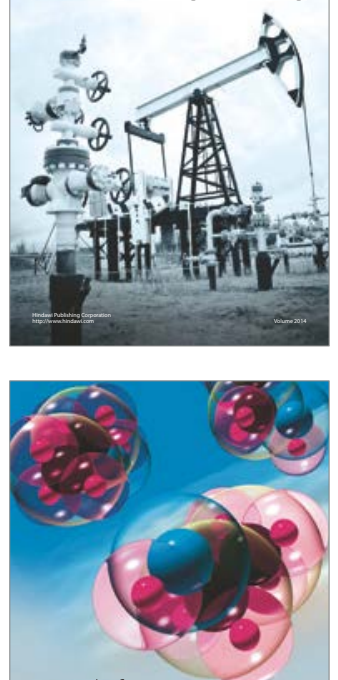

Fuels
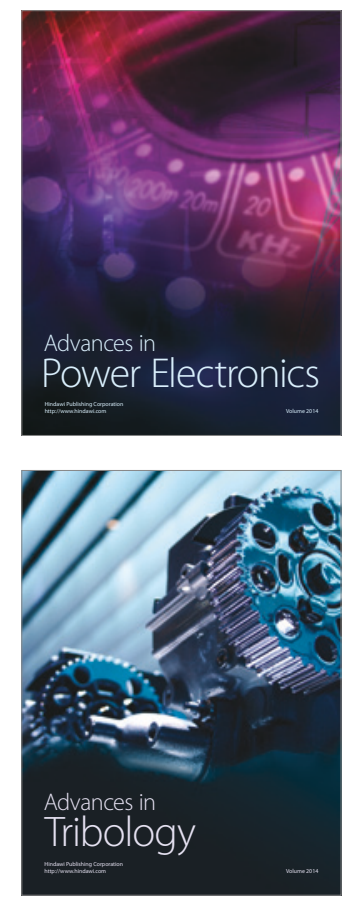
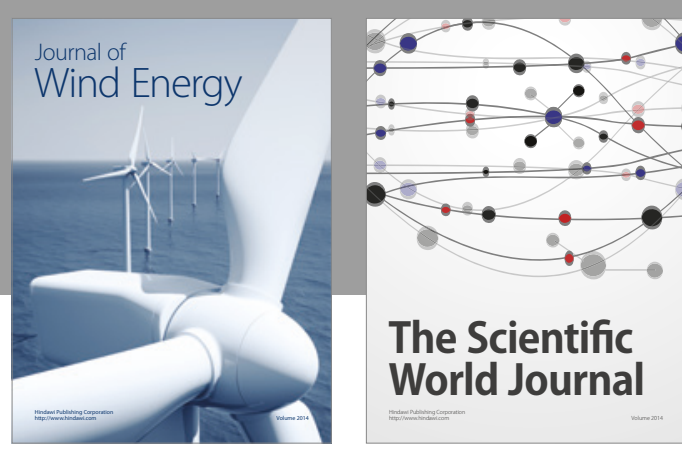

The Scientific World Journal
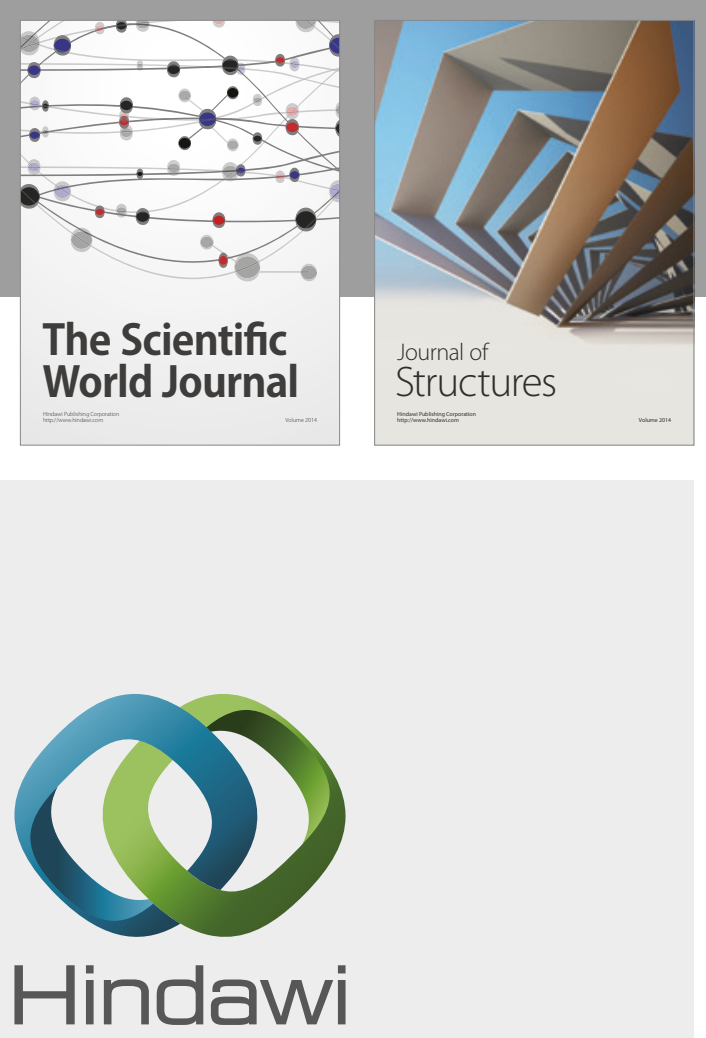

Submit your manuscripts at

https://www.hindawi.com
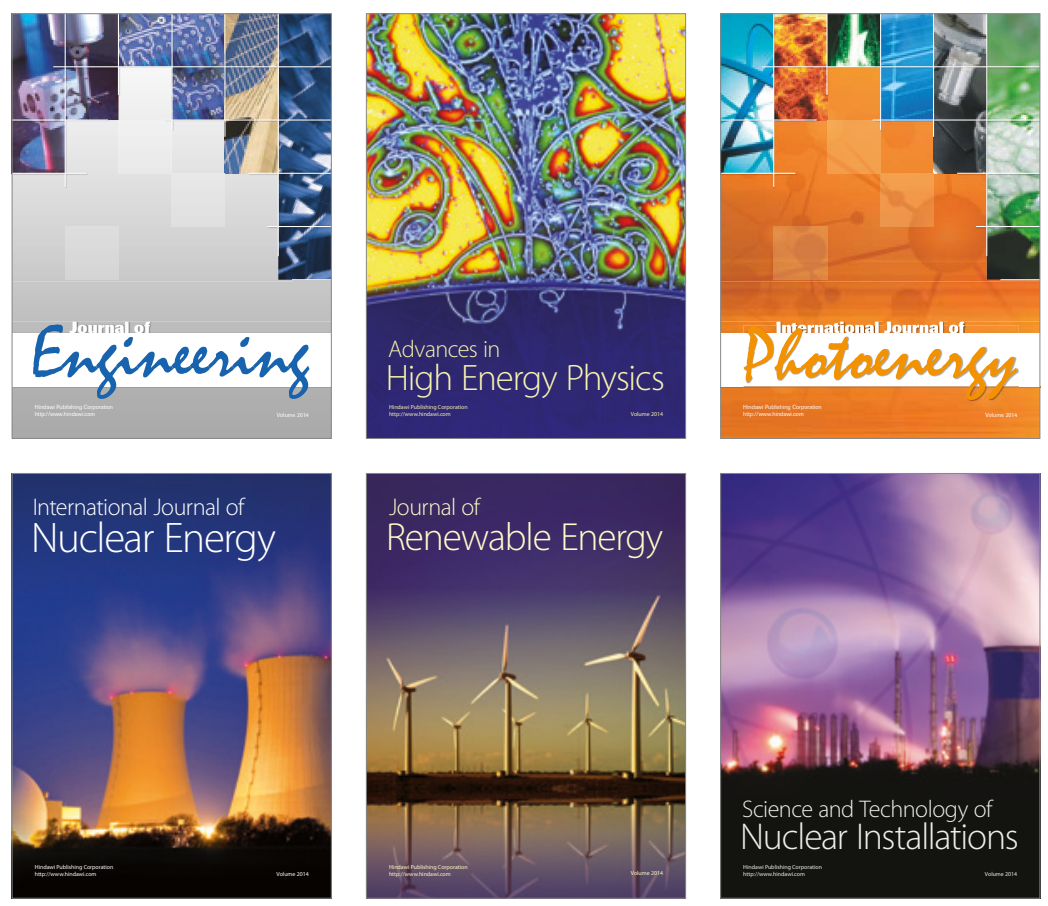

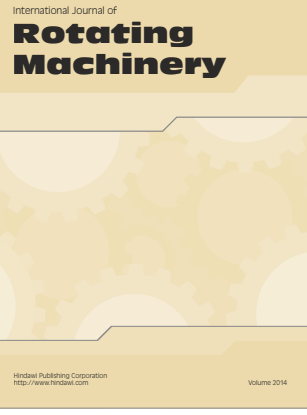

Journal of

Petroleum Engineering

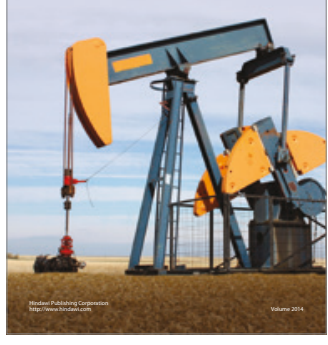

Journal of
Solar Energy
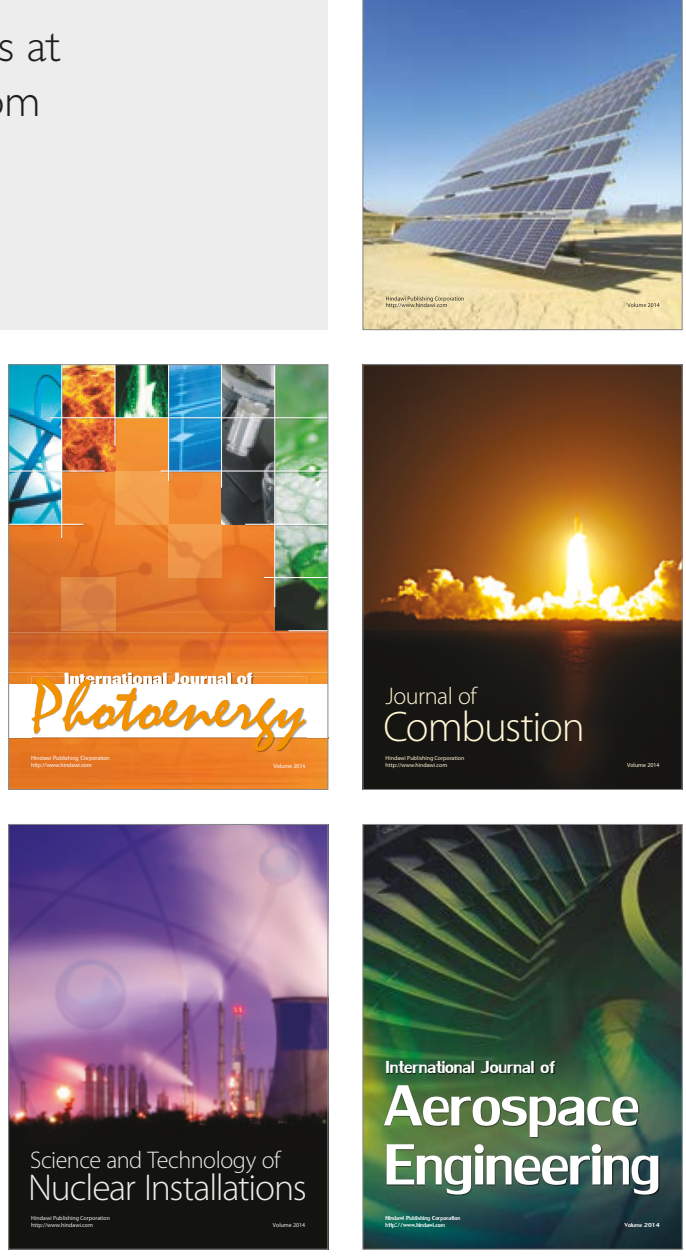